\title{
Development process for tar filtering from biomass pyrolysis
}

\author{
A. N. Rozhan \& H. Purwanto \\ Department of Manufacturing and Materials Engineering, \\ International Islamic University, Malaysia
}

\begin{abstract}
This paper presents a new approach for recovering tar produced from the biomass pyrolysis process. Pyrolysis is a promising thermochemical process to utilize biomass to produce gas, char and tar. Tar is a vapour/liquid product containing carbon, and it is often found in producer gas. It needs to be recovered from gas mixture to upgrade its value for the tar to be utilized on its own as a fuel source. In this developed process, steelmaking slag and low-grade iron ore were made porous by the dehydration process, and were then introduced as a tar filter to trap tar produced during biomass pyrolysis. The purpose of this work is to investigate the possibility of using porous materials for tar filtering during the pyrolysis process. Tar vapour infiltrates the porous materials and then decomposes into carbon and gases, where carbon is deposited on the pore surface. Clean gas can be collected and tar can be recovered before being utilized as a renewable energy source by itself. After the trapping process, carbon was found to be deposited within the porous material. The product of the tar filtering will be carbon-deposited material - a potential candidate to be used as a renewable fuel source.

Keywords: porous materials, pyrolysis, biomass, tar filter, renewable fuel source.
\end{abstract}

\section{Introduction}

Thermochemical process is one of the most important routes of biomass conversion, and pyrolysis is a promising and prominent thermochemical process since it requires a low energy input. Pyrolysis produces materials that can be used as fuels such as gases, char - a highly carbonaceous solid material, and tar. Tar is a vapour/liquid product containing carbon and is normally found in gas mixture in the form of soot or pyrocarbon [1], produced by pyrolysis or gasification. It is a constituent that is combusted together with fuel gases and produced from pyrolysis and/or gasification. This reduces the potential benefits of tar to be used as an 
alternative energy source. The carbon content in tar is a highly potential renewable energy source, which should be fully utilized in either its gaseous, liquid or solid form.

In many industries, coal, an important non-renewable fossil fuel has been extensively utilized as a source of energy, and is now unfortunately facing depletion [2]. By understanding the limited availability of coal at present, it is reasonable to consider utilization of renewable resources such as biomass as an alternative. Recent studies by Yunos et al. [3], Ueki et al. [4] and Suopajarvi et al. [5] have proven that biomass can be a good candidate to partially replace coke in steel works, and tar is a potential constituent to be recovered from producer gas to be used in the form of solid fuel. Studies by Devi et al. [6], Pfeifer and Hofbauer [7] and Liu et al. [8] have been conducted to decompose these tars into gases by the gasification process, and porous materials such as olivine have always been used as the catalysts. The temperatures used in this process are reported to be more than $700^{\circ} \mathrm{C}$ to ensure tar is fully converted into clean fuel gases.

In steelworks, slag is the major byproduct and has been continuously and abundantly produced in this industry, which primarily contains silica and alumina from iron ore, combined with calcium oxide from the flux [9]. Slag contains a high content of free lime and iron oxide [10], which is beneficial when recycled in the iron making process, instead of being dumped abundantly at the sites, as in current practice.

Low-grade iron ores are largely available in countries such as Malaysia, Indonesia and Australia. This type of iron ore contains more gangue materials and combined water than those of high-grade iron ores [11, 12]. Studies by Hata et al. [13], Rozhan et al. [14] and Cahyono et al. [15] have reported that by heating these low-grade iron ores at temperatures less than $500^{\circ} \mathrm{C}$, thermal decomposition of $\mathrm{FeO}(\mathrm{OH})$ removes the combined water, leaving the iron ore porous. However, additional thermal energy is required if low-grade iron ore is used directly in the iron-making process, which makes the utilization of low-grade iron ore less energy efficient.

In this study, porous steelmaking slag and low-grade iron ore were used as tarfiltering materials, implementing the tar decomposition process at temperatures lower than those of the gasification process. Tar decomposition occurred at $500^{\circ} \mathrm{C}$ by a mechanism where tar vapour infiltrates within the porous ore and decomposes, leaving solid carbon on the pore surface. The trapped carbon can be an energy source to help reduce the utilization of coal in industries. Biomass, when used as a supplementary fuel, shows a significant reduction in $\mathrm{CO}_{2}$ emmission [16], which makes is a good candidate for being utilised as an alternative energy source.

\section{Materials and method}

\subsection{Materials preparation}

The raw materials used as precursors in this study are steelmaking slag and lowgrade iron ore. Both materials contain - $\mathrm{OH}$ group, which can be removed by the heat treatment process to create an increased amount of pores within the materials. 


\subsubsection{Steelmaking slag}

The main component of steelmaking slag used in this study was $\mathrm{Ca}(\mathrm{OH})_{2}$. For preparation, slag which contains 12 mass\% of hydrates was sieved to 1-2 cm before being heated in an electric furnace for dehydration. Dehydration was performed by heating the slag in the electric furnace to $450^{\circ} \mathrm{C}$ at a heating rate of $1^{\circ} \mathrm{C} / \mathrm{min}$. The holding time was 3 hours. This condition was chosen after conducting preliminary experiments to obtain the favourable pore characteristics of the slag for the next process, which is the tar-carbonization process.

\subsubsection{Low-grade iron ore}

The iron ore used in this study is from Pahang, Malaysia. The total iron content was 49.73 mass\%, and therefore was considered a low-grade iron ore. For preparation, iron ore was first pulverized and sieved to $1-2 \mathrm{~cm}$ as preparation. This iron ore contains geothite, $\mathrm{FeO}(\mathrm{OH})$ and 5.90 mass\% of combined water. In order to remove the water content, iron ore was put in an electric furnace and heated up to $500^{\circ} \mathrm{C}$ at a heating rate of $3^{\circ} \mathrm{C} / \mathrm{min}$ and held for 10 hours to ensure complete removal of combined water. After the removal of combined water, an increased amount of pores was observed in the iron ore.

\subsection{Experiments of tar filtering}

Japanese pine sawdust (PS) and palm solid wastes, empty fruit bunch (EFB), palm fiber (PF), and palm kernel shell (PKS) were used in this study and they were sieved to $210-350 \mu \mathrm{m}$ and $350-510 \mu \mathrm{m}$, respectively. The elemental compositions of the biomass are presented in Table 1.

Table 1: Elemental compositions of biomass in mass \%.

\begin{tabular}{|l|c|c|c|}
\hline Biomass [d.a.f] & C & H & O* $^{*}$ \\
\hline Pine Sawdust, PS & 49.83 & 6.18 & 43.99 \\
\hline Empty fruit bunch, EFB & 45.64 & 6.19 & 48.17 \\
\hline Palm fiber, PF & 45.84 & 6.18 & 47.98 \\
\hline Palm kernel shell, PKS & 49.48 & 5.69 & 44.83 \\
\hline
\end{tabular}

*O was calculated by difference.

Figure 1 shows the experimental apparatus in a schematic diagram. Biomass was fed from a feeder into the pyrolysis chamber, which was preheated to an experimental temperature of $500^{\circ} \mathrm{C}$ together with flowing nitrogen gas. Char formed from the flash pyrolysis, which was collected in a stainless steel mesh, and tar vapour and gases were allowed to flow into the packed bed, which contains precursor material.

In the first part, experiments were carried out using a steelmaking slag as the precursor material and PS as the biomass. Approximately 3.0g of dehydrated slag was put in the packed bed for each experiment. PS was being fed from the feeder into the chamber at a rate of $0.07 \mathrm{~g} / \mathrm{min}$. Tar vapour was introduced into the bed of porous slag where it infiltrated within the pores and decomposed into carbon and 


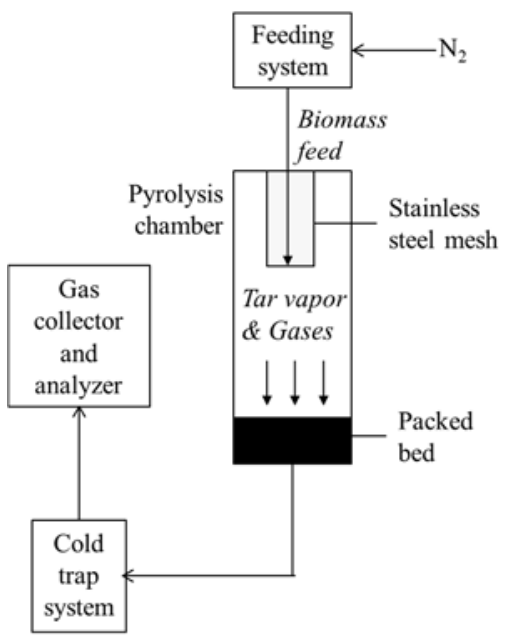

Figure 1: Schematic diagram of experimental apparatus.

gases when tar vapour came in contact with the pore surface. The residual gases were collected in the cold trap at $-75^{\circ} \mathrm{C}$. The experimental time was 40 minutes. Experiments were repeated by increasing the experimental time to 60 and 80 minutes to compare the results.

In the second part, porous low-grade iron ore was used as the precursor material with palm solid wastes, EFB, PF and PKS used as the biomass. 3.0g of porous low-grade iron ore was put in a packed bed and the experimental temperature was set at $500^{\circ} \mathrm{C}$. The biomass feeding rate was $0.10 \mathrm{~g} / \mathrm{min}$. The experimental time was set at 60 minutes and the experiments were carried out for EFB, PF and PKS individually.

After carbonization process, characterizations were done on the resultant materials. $\mathrm{N}_{2}$ adsorption equipment was used to analyze the pore characteristics. Brunauer-Emmet-Teller, BET method and Barrett-Joyner-Halenda, BJH method were employed to obtain the specific surface area and pore size distribution of each product. The carbon contents within the porous precursor materials were examined using elemental analysis by combustion.

\section{Results and discussions}

The materials used in this study included steelmaking slag, which contains 12.0 mass\% hydrates and iron ore with 5.90 mass\%, combined water. For steelmaking slag, after the dehydration process was carried out at $450^{\circ} \mathrm{C}$ in an electric furnace, the following chemical reaction occurred: $\mathrm{Ca}(\mathrm{OH})_{2} \rightarrow \mathrm{CaO}+\mathrm{H}_{2} \mathrm{O}$; and after this dehydration process, the material obtained was $\mathrm{CaO}$, with an increased porosity and specific surface area - an interesting property to filter and/or trap tar. On the other hand, for iron ore, combined water was removed to create pores and the reaction occurred was as follows: $2 \mathrm{FeO}(\mathrm{OH}) \rightarrow \mathrm{Fe}_{2} \mathrm{O}_{3}+\mathrm{H}_{2} \mathrm{O}$. 
Figure 2 shows the changes in specific surface area and total pore volume of porous precursor materials, steelmaking slag and iron ore, before and after the heat treatment, and after tar carbonization process at $500^{\circ} \mathrm{C}$ for 60 minutes. After heat treatment to remove hydrates from the steelmaking slag and combined water from low-grade iron ore, the total pore volume increased, thus causing the specific surface area to also increase. For the steelmaking slag, the total pore volume and the specific surface area increased from 80.6 to $136.6 \mathrm{~m}^{3} / \mathrm{kg}$ and from 33.8 to $54.0 \mathrm{~m}^{2} / \mathrm{g}$, respectively.

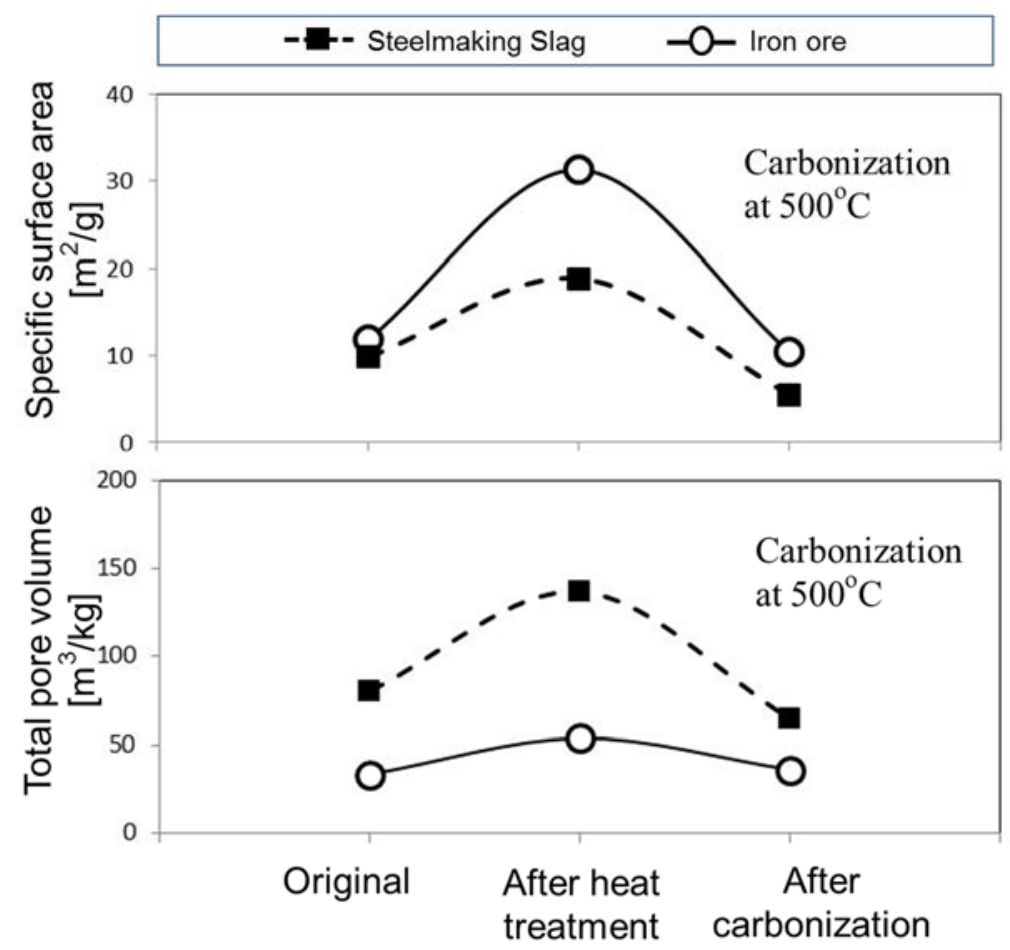

Figure 2: Specific surface area and total pore volume of tar-filtering materials, steelmaking slag and iron ore, where tar was obtained from the fast pyrolysis of pine sawdust, PS and empty fruit bunch, EFB respectively. Specific surface area and pore volume increased after dehydration because of the increase in porosity after heat treatment. After carbonization, tar was trapped within the pores, hence the decrease in surface area and pore volume.

After the tar carbonization process, the porosity was found to be reduced to the total pore volume of $64.71 \mathrm{~m}^{3} / \mathrm{kg}$ for steelmaking slag and $36.4 \mathrm{~m}^{3} / \mathrm{kg}$ for the lowgrade iron ore. This is due to tar carbonization and carbon deposition within the pores. This is proven by the pore size distribution curves shown in Figures 3 and Figure 4. 


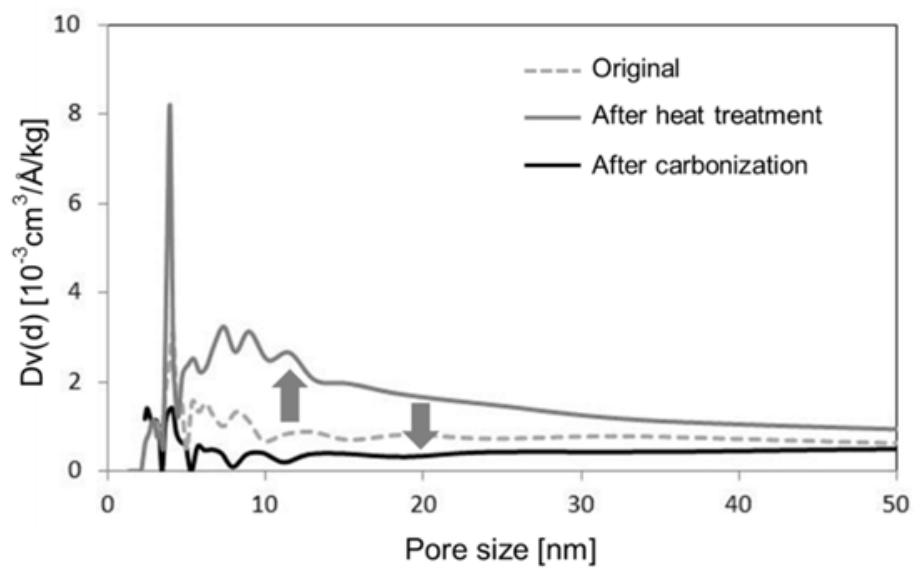

Figure 3: Changes in pore size distribution of steelmaking slag before heat treatment, after heat treatment, and after carbonization at $500^{\circ} \mathrm{C}$; tar source was pine sawdust, PS.

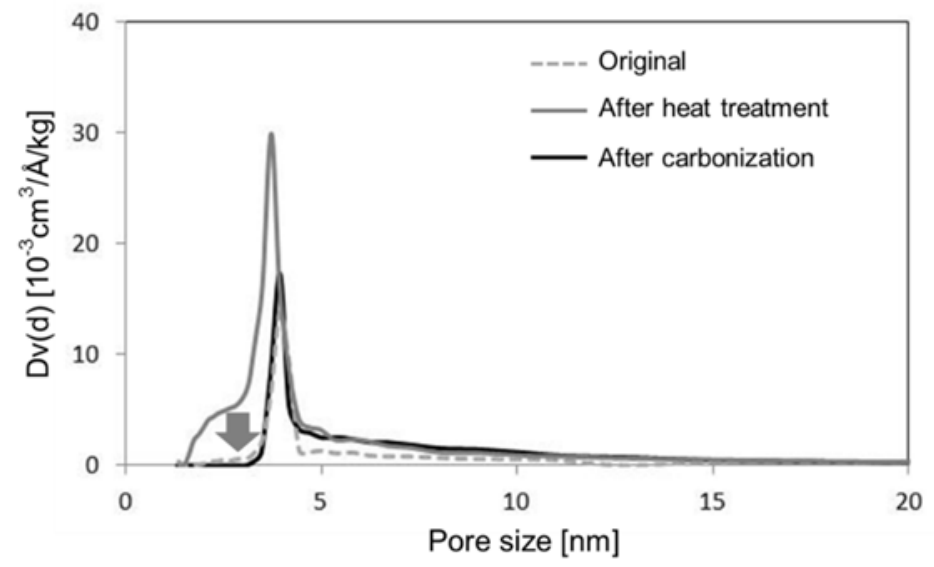

Figure 4: Changes in pore size distribution of low-grade iron ore before heat treatment, after heat treatment, and after carbonization at $500^{\circ} \mathrm{C}$; tar source was empty fruit bunch, EFB.

In Figures 3 and 4, it can be seen that the area under the curves increased after heat treatment and decreased after the tar carbonization process; which indicate the pore creation and pore consumption, respectively.

In this study, the experiments were designed so that the biomass produces a large amount of tar during the pyrolysis process in order to observe the tar-filtering process. Flash pyrolysis was employed because the main product of this process is tar, and a small particle size is favourable to obtain a higher tar yield. Note, the 
tar-filtering materials were made porous beforehand so that during the experiments, tar could be infiltrated within the materials and decomposed into carbon and gases. The equation of tar decomposition is simplified as below:

$$
\text { Tar } \rightarrow \mathrm{C}(\mathrm{s})+\mathrm{H}_{2}(\mathrm{~g})+\mathrm{CO}(\mathrm{g})+\mathrm{CO}_{2}(\mathrm{~g})+\mathrm{CH}_{4}(\mathrm{~g})+\text { other hydrocarbons }
$$

In this process, tar vapour infiltrated within the porous bodies, and tar decomposition occurred on the pore surface, where carbon was deposited. The remaining gases that could be used as fuel were removed from the porous body and collected in a gas bag.

Figure 5 shows the carbon contents of steelmaking slag and low-grade iron ore after tar carbonization experiments were complete. The amount of carbon content found within the steelmaking slag were higher than that of the low-grade iron ore. This is because of the larger total pore volume of the steelmaking slag, as shown in Figure 2. The pore consumption after tar carbonization was also very large for the steelmaking slag (Figure 3) as compared with that of the low-grade iron ore (Figure 4).

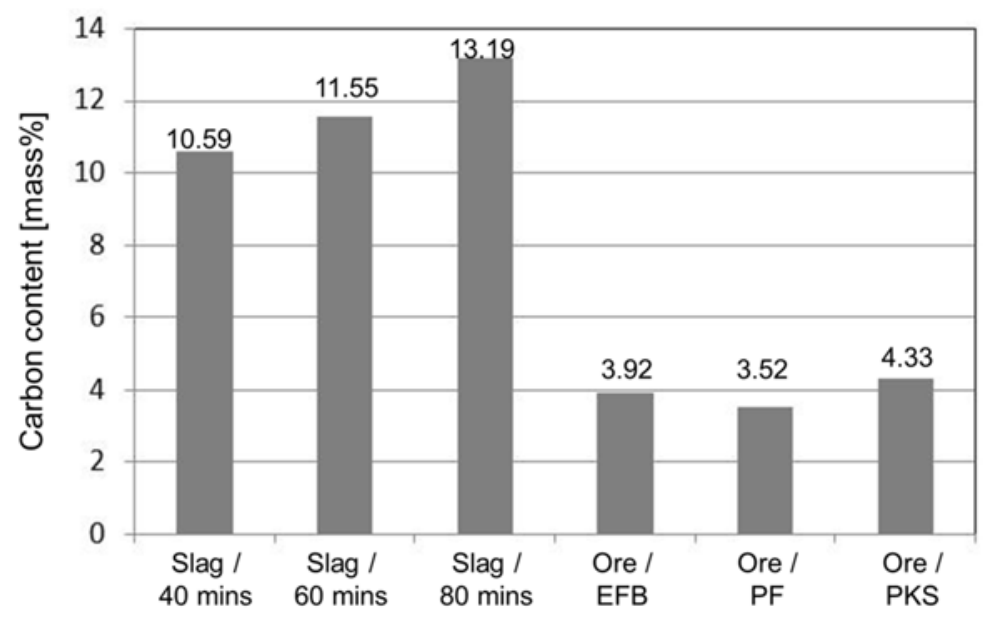

Figure 5: Carbon contents of steelmaking slag after tar carbonization at $500^{\circ} \mathrm{C}$ for 40-60 minutes; and those of low-grade iron ore after tar carbonization at $500^{\circ} \mathrm{C}$ using EFB, PF and PKS as biomass. Carbon contents were tested using elemental analysis by combustion.

For the steelmaking slag, the amount of carbon content increased with experimental time because of the larger amount of biomass feed. The carbon contents were $10.59,11.55$, and 13.19 mass $\%$ for experiments conducted for 40 minutes, 60 minutes and 80 minutes, respectively. For low-grade iron ore, the amount of carbon differed for each experiment using EFB, PF and PKS. This is because different types of feedstock used give their own unique results. When comparing the experiments that use these palm solid wastes, experiments 
conducted using PKS gave the largest carbon content, followed by EFB and PF; with carbon contents of 3.92, 3.52 and 4.33 mass\%, respectively.

The results indicated that porous steelmaking slag and porous low-grade iron ore can be used as tar-filtering materials to trap tar, for the tar to be used as an alternative renewable fuel source.

\section{Conclusions}

Porous steelmaking slag and porous low-grade iron ore were used as tar-filtering materials, trapping tar produced from the flash pyrolysis of biomass. The biomasses used in this study were pine sawdust and palm solid wastes; empty fruit bunch, palm fiber and palm kernel shell. Carbon contents were investigated to observe the tar-filtering process. Carbon was found deposited within the porous steelmaking slag and porous low-grade iron ore.

The results obtained have proven that porous materials can be used for tar-filtering process. The tar decomposition reaction will occur on the pore surface to produce carbon, which will be deposited within the porous bodies. Carbon deposits within the porous bodies is essential; specifically in steelworks, since the contact area between carbon and iron oxides is increased for both steelmaking slag and low-grade iron ore.

Overall, this study suggests the possibility of using tar vapour to be converted into solid carbon, as an alternative renewable energy source. The proposed technology is implemented to recover tar that is being produced during the biomass pyrolysis process but not recovered. This tar will be able to be utilized in the form of solid carbon to partially replace coal as fuel, and also for easier and more economical transportation. Biomass as a supplementary fuel gives a significant reduction of $\mathrm{CO}_{2}$ emission, and therefore, an improved sustainability.

\section{References}

[1] Vreugdenhill, B. J. \& Zwart, R. W. R., Tar Formation in Pyrolysis and Gasification. Energy Research Centre of the Netherlands: Petten, The Netherlands, ECN-E--08-087, 2009.

[2] Iron Nugget Xchange. Tomorrow's Ironmaking; Iron Nugget Xchange: Tokyo, Japan, 2011, http://www.ironxch.com/technology03.html

[3] Yunos, N. F. M., Zaharia, M., Idris, M. A., Nath, D., Khanna, R. \& Sahajwalla, V., Recycling agricultural waste from palm shells during electric arc furnace steelmaking. Energy Fuels, 26(1), 278-286, 2012.

[4] Ueki, Y., Yoshiie, R., Naruse, I., Ohno, K., Maeda, T., Nishioka, K. \& Shimizu, M., Reaction behavior during heating biomass materials and iron oxide composites. Fuel, 104, 58-61, 2013.

[5] Suopajarvi, H., Pongracz, E. \& Fabritius, T., The potential of using biomass-based reducing agents in the blast furnace: A review of thermochemical conversion technologies and assessments related to sustainability. Renewable and Sustainable Energy Reviews, 25, 511-528, 2013. 
[6] Devi, L., Ptasinski, K. J., Janssen, F., Paasen, S., Bergman, P. \& Kiel, J., Catalytic decomposition of biomass tars: Use of dolomite and untreated olivine. Renewable Energy, 30(4), 565-587, 2005.

[7] Pfeifer, C. \& Hofbauer, H., Development of catalytic tar decomposition downstream from a dual fluidized bed biomass steam gasifier, Powder Technology, 180(1-2), 9-16, 2008.

[8] Liu, H., Chen, T., Chang, D., Chen, D. \& Frost, R. L., Catalytic cracking of tars derived from rice hull gasification over goethite and palygorskite, Applied Clay Science, 70, 51-57, 2012.

[9] National Slag Association. The Construction Material of Choice; National Slag Association: Wayne, PA, 2011, http://ebookbrowse.com/nsa-blastfurnace-brochure-pdf-d106121148

[10] Waligora, J., Bulteel, D., Degrugilliers, P., Damidot, D., Potevin, J. L. \& Measson, M., Chemical and mineralogical characterizations of LD converter steel slags: A multi-analytical techniques approach. Materials Characterization, 6, 39-48, 2010.

[11] Dwari, R. K., Rao, D. S. \& Reddy, P. S. R., Magnetic separation studies for a low grade siliceous iron ore sample. International Journal of Mining Science and Technology, 23(1), 1-5, 2013.

[12] Seifelnassr, A. A. S., Moslem, E. M. \& Abouzeid, A. Z. M., Concentration of a Sudanese low-grade iron ore. International Journal of Mineral Processing, 122, 59-62, 2013.

[13] Hata, Y., Purwanto, H., Hosokai, S., Hayashi, J., Kashiwaya, Y., and Akiyama, T., Biotar ironmaking using wooden biomass and nanoporous iron ore. Energy Fuels, 23, 1128-1131, 2009.

[14] Rozhan, A. N., Cahyono, R. B., Yasuda, N., Nomura, T., Hosokai, S., Purwanto, H. \& Akiyama T., Carbon deposition of biotar from pine sawdust by chemical vapor infiltration on steelmaking slag as a supplementary fuel in steelworks. Energy Fuels, 26, 7340-7346, 2012.

[15] Cahyono, R. B., Rozhan, A. N., Yasuda, N., Nomura, T., Hosokai, S. \& Akiyama, T., Catalytic coal-tar decomposition to enhance reactivity of lowgrade iron ore. Fuel Processing Technology, 113, 84-89, 2013.

[16] Zandi, M., Pacheco, M. M. \& Fray, T. A. T., Biomass for iron ore sintering. Minerals Engineering, 23, 1139-1145, 2010. 